\title{
Modification of the tear function index and its use in the diagnosis of Sjögren's syndrome
}

\author{
Stephen B Kaye, Gillian Sims, Colin Willoughby, Anne E Field, Lesley Longman, \\ Malcolm C Brown
}

\begin{abstract}
Background-The tear function index (TFI) has been shown to be of value in the diagnosis of patients suffering from Sjögren's syndrome. It is dependent, however, on introducing into the conjunctival fornix the correct concentration of fluorescein in at least one and a half times the normal tear volume. The stimulus and effect of this added volume on the tear dynamics is likely to vary between individuals. These factors, together with the method of performing the test, limit its general applicability.

Aim-To devise a method of performing the TFI with less variability and more general applicability. To present a theoretical and in vitro assessment of the dynamics of the TFI.

Method-The study was divided into three parts. The first part was to compare the results obtained using a prepared strip containing $1.3 \mu \mathrm{l}$ of $0.5 \%$ fluorescein with the introduction of the same amount of fluorescein as a drop. The second part was to compare the results obtained with prepared strips with the standard method of performing the TFI, both with and without topical anaesthetic. The third part was an in vitro study of the rate of flow of graded volumes on a filter paper strip. 42 subjects with a diagnosis of Sjögren's syndrome according to the European criteria and 126 without Sjögren's syndrome were included.
\end{abstract}

Results-There was no significant difference between the results obtained with a prepared strip and the introduction of $1.3 \mu \mathrm{l}$ into the eye before performing the Schirmer's test and TFI $(0.1<p<0.93)$. There was, likewise, no significant difference between using the prepared strips and the standard method of performing the TFI $(0.36<p<0.93)$. There was, however, less interocular difference $(p=0.01)$ and variability $(p=0.001)$ using the prepared strips than using a drop of fluorescein. Patients with Sjögren's syndrome had mean TFIs of 11.7 and 8.61 with upper $95 \%$ confidence values of 15 and 12 without and with topical anaesthetic, respectively. The theoretical calculation of the TFI was similar to the observed values. The in vitro results allow the filter paper to be removed from the eye at any interval and to estimate the volume of tears that the filter paper was in contact with.
Conclusion-The proposed method of performing the TFI is easy to perform, reliable, and therefore has general applicability for primary care and general practitioners. It allows the rapid identification of subjects who may be suffering from Sjögren's syndrome.

(Br F Ophthalmol 2001;85:193-199)

The Schirmer's test is widely used in the diagnosis of dry eye syndrome. It has, however, a low sensitivity, specificity, and reproducibility. ${ }^{1-6}$ As one of the factors influencing the results of the Schirmer's test is tear drainage, the tear clearance rate $(\mathrm{TCR})^{7}$ was developed as a modified form of the fluorescein clearance test. ${ }^{8}$ The quotient of the Schirmer's test and TCR, that is the tear function index (TFI) developed by $\mathrm{Xu}$ et $a l^{9}$ reflects both secretory and drainage conditions. The TFI was reported by $\mathrm{Xu}$ et $a l^{9}$ to provide better separation of normal, non-Sjögren's syndrome and Sjögren's syndrome dry eye patients, with better sensitivity and specificity than the Schirmer's or TCR alone.

The TFI is performed by instilling fluorescein into the conjunctival fornix, followed by a Schirmer's test. The colour (dilution) of the fluorescein on the filter paper strip is then compared with known standards to give the TCR; the TFI is then calculated by dividing the Schirmer's value by the TCR. This method is, however, dependent on using a micropipette to instil the correct amount $(10 \mu \mathrm{l})$ and concentration of fluorescein into each eye. It is also necessary for the Schirmer's test to be performed at a specific time-that is, 5 minutes after instillation of fluorescein into the conjunctival fornix. Furthermore, instilling $10 \mu \mathrm{l}$ of fluorescein (at least 1.5 times the normal tear volume) increases the tear volume and acts as a stimulant, so that the tear volume may not have returned to its initial value after 5 minutes, before commencement of the Schirmer's test. This may then lead to an artificially high Schirmer's test and TFI, particularly in patients who have abnormalities of tear drainage. These factors limit the general application of the TFI in practice. The purposes of this study were to devise a practical method for performing the TFI, and to present a model to describe the volume, distance, and time characteristics associated with the Schirmer's test and TFI.

\section{Study design}

The first part of the study was to determine clinically whether the introduction of a drop of
Accepted for publication 16 June 2000 
fluorescein into the conjunctival fornix produced the same TCR and TFI as using a filter paper strip with one end impregnated with the same amount of fluorescein. The standard technique of performing the $\mathrm{TFI}^{9}$ uses $10 \mu \mathrm{l}$ of $0.5 \%$ fluorescein placed into the conjunctival fornix 5 minutes before performing the TFI. As this amount - that is, $10 \mu \mathrm{l}$ of fluorescein, would wet the filter strip to approximately 20 $\mathrm{mm}$, prepared strips containing this amount of fluorescein could not be used. In addition, although it is possible to approximate the amount and concentration of fluorescein remaining in the tear film after 5 minutes for given parameters (as discussed below), because tear film secretion, evaporation, and drainage vary between individuals, different amounts and concentrations of fluorescein would, therefore, be present after 5 minutes. Thus, because the volume of fluorescein remaining in the eye after 5 minutes is unknown, comparison of the TFI using a prepared strip or drop of fluorescein needed first to be assessed by introducing the same amount of fluorescein in the drop as in the prepared strip, immediately before performing the Schirmer's test. The initial part of the study therefore, was to determine whether a prepared strip containing the same amount of fluorescein as a drop produced the same dynamics as reflected in the TCR and TFI. Providing this could be demonstrated, the second part of the study was to determine whether a prepared strip produced similar results to the standard method of performing and measuring the TFI. This would also allow the determination of confidence intervals for normal subjects and for those with an established diagnosis of Sjögren's syndrome.

To determine a theoretical model for the TFI to assess the in vivo results, in vitro data were collected for the distance and rate of flow of graded volumes on strips of filter paper. Best fit curves were then used to characterise flow along the filter paper strip. A mathematical model was developed to determine the theoretical TFI and this was compared with the in vivo results.

\section{Methods}

Filter paper strips (Sno strips, Chauvin Pharmaceuticals Ltd) were used for the study. These strips are frequently used in the UK and are $5 \mathrm{~mm}$ in width for the first $15 \mathrm{~mm}$ and 6.5 $\mathrm{mm}$ in width for the remaining $25 \mathrm{~mm}$. Filter paper strips were prepared by placing $1.3 \mu \mathrm{l}$ of $0.5 \%$ fluorescein (Chauvin Pharmaceuticals Ltd) onto the end of the filter paper strip. This volume was chosen as it resulted in staining of the filter paper up to the notch of the strip (Fig 1). The prepared strips were then air dried and stored in a sterile universal container for not longer than 1 week until use.

PART ONE: FLUORESCEIN FILTER PAPER STRIP COMPARED TO EQUIVALENT AMOUNT OF FLUORESCEIN

The Schirmer's test, TCR, and TFI were performed either by placing a prepared strip containing fluorescein or by placing $1.3 \mu \mathrm{l}$ of $0.5 \%$

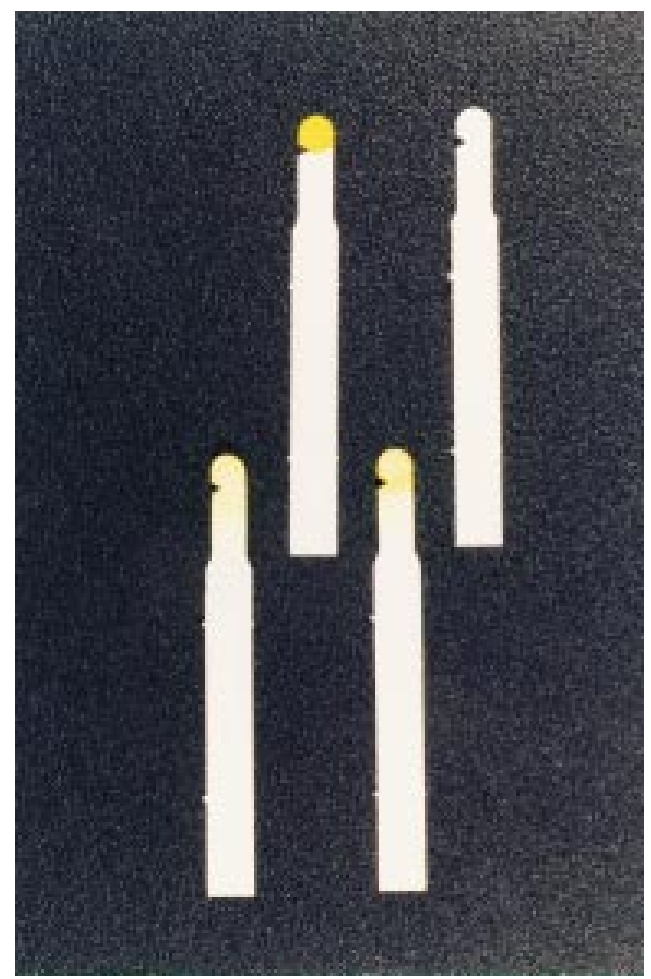

Figure 1 Prepared strip containing $1.3 \mu \mathrm{l}$ of $0.5 \%$ fluorescein and plain filter strip (upper row). Subject received $10 \mu \mathrm{l}$ of $0.5 \%$ fluorescein into left eye 5 minutes before placement of filter paper strips. Prepared strip (right) and plain strip (left) removed from subjects eyes after 5 minutes (lower row).

fluorescein into the lower conjunctival fornix, followed (approximately 5 seconds later) by the placement of a strip of filter paper over the junction of the middle and lateral third of the lower lid. The right eye always received the filter strip first, followed by the left eye within 5 seconds. The test was performed with the subject's eyes closed. This was in order to reduce the variation produced by evaporation, which is dependent on the surface area and hence the size of the palpebral aperture, particularly for patients with Sjögren's syndrome ${ }^{10-12}$ who may have increased ${ }^{10}{ }^{11}$ or decreased ${ }^{12}$ evaporation rates. The effect of this is that patients with keratoconjunctivitis sicca (KCS) may lose the majority of their tear film through evaporation, compared with a $10 \%$ loss of the normal tear production. ${ }^{10}$

After 3 minutes (part one) the filter paper was removed and the distance of the end of the wetted portion to the notch measured to the nearest millimetre. Three minutes was chosen for the first part of the study in order to minimise subject discomfort and because approximately $90 \%$ of wetting of the filter strip occurs in the first 3 minutes. ${ }^{2}$ The filter paper was then allowed to air dry and the colour of the filter paper, between the notch and wet mark, was compared with a standard dilution range. The standard dilution range was prepared using doubling dilutions of fluorescein starting at $0.5 \%$ and diluting to $1: 128 .^{8}{ }^{9} \mathrm{~A}$ TCR of 1 , therefore, reflects a concentration of fluorescein of $0.5 \%$. The most comparable colour dilution was chosen by the observer and recorded as the TCR. Each strip of filter paper 
was read on three separate independent occasions by an independent observer who was blind to the aim of the study. The Schirmer's value was then divided by the TCR to give the TFI.

Although there is considerable variability in the reproducibility of the within-eye Schirmer's test, ${ }^{1-6}$ the within-subject results for right and left eyes are similar with no significant difference. ${ }^{12}$ It was decided, therefore, to compare within-subject right and left eyes using a prepared strip in one eye and a drop in the other and vice versa, a prepared strip into both eyes and a drop into both eyes, and then to compare the interocular difference for each test procedure. The right eye received both the drop and filter paper first, so that the delay between receiving the drop and filter paper was equivalent for right and left eyes.

Because of the exponential scale for the TCR and TFI, the data were converted to logarithmic form. ${ }^{9}$ The natural logarithm of the right to left ratio for the TFI and TCR, therefore, reflects the interocular difference. Differences in means and within-eye and within-group variances were then compared using an $\mathrm{F}$ test.

PART TWO: STANDARD TFI VERSUS FLUORESCEIN IMPREGNATED FILTER PAPER STRIP

Ten $\mu \mathrm{l}$ of $0.5 \%$ fluorescein were placed into the conjunctival sac of one eye 5 minutes before performing a Schirmer's test and placing a prepared filter strip into the fellow eye. Subjects were requested to keep their eyes closed, and the filter strips were removed after 5 minutes. Thirty to 60 minutes later, the procedure was repeated, except that the $10 \mu$ dilution of $0.5 \%$ fluorescein was made using $0.4 \%$ oxybuprocaine (Chauvin Pharmaceuticals) as the diluent and $10 \mu \mathrm{l}$ of $0.4 \%$ oxybuprocaine was placed into the conjunctival fornix of the fellow eye. Five minutes later a filter strip was placed into the eye receiving the $10 \mu \mathrm{l}$ of fluorescein and a prepared filter strip placed into the eye that received $10 \mu \mathrm{l}$ of oxybuprocaine. Subjects were consecutively alternated for either the left or right eye to receive the prepared strip. If the right eye received the drop of fluorescein, then the left eye would receive the drop of fluorescein with oxybuprocaine. Filter paper strips were then removed, air dried, and read as in part one.

Patients were excluded if both parts of the test-that is without and with topical anaesthetic, could not be completed, if they had unilateral external eye disease, if they had had any previous ocular surgery, or if they were using any topical medication to either eye.

SUBJECTS

A diagnosis of Sjögren's syndrome was made according to the diagnostic criteria proposed by the European Community Study Group. ${ }^{13}$ Salivary gland involvement was ascertained by measurement of whole, unstimulated salivary flow under standardised conditions ${ }^{14}$ and scintigraphy (radioisotope study of salivary gland function using technetium pertechnetate, $\left.{ }^{99 \mathrm{~m}} \mathrm{Tc}\right)^{15}{ }^{16}$; labial gland biopsy was undertaken by an oral physician using a standardised technique. ${ }^{16}$ Patients were included with definite Sjögren's syndrome if they had four or more of the European criteria $^{13}$ for a diagnosis of Sjögren's syndrome, including the presence of autoantibodies. ${ }^{13}$

Patients were assessed for evidence of meibomian disease using the features described by Bron et al, ${ }^{17}$ Shimazaki et $a l,{ }^{18}$ and Pflugfelder et $a l^{19}$ Patients were included if they were diagnosed as having obstructive meibomian gland ductules (MGD): irregularity of the lid margins, vascularity and retro placement of mucocutaneous junction; involvement of at least $30 \%$ of the meibomian glands with metaplasia of the MGD, and obstruction of at least three out of five glands using the method of Pflugfelder et al. ${ }^{19}$ That is, digital compression of the lower lid just below the lash line and the upper lid just above the lash line against the globe over an area spanning five visible meibomian gland orifices. ${ }^{20}$

PART THREE: IN VITRO DISTANCE AND RATE OF FLOW OF GRADED VOLUMES ON FILTER PAPER STRIPS

To determine the volume distance and volumetime relation using a filter strip, the following method was adopted. The filter paper strip was folded at the notch, which is situated $5 \mathrm{~mm}$ from the rounded end, and placed over the edge of a thin glass plate, with the remainder of the strip hanging vertically-similar to the method of Clinch et al. ${ }^{2}$ A millimetre ruler was situated alongside the filter paper. A drop of fluorescein $2 \%$ was placed on the first, horizontal part of the strip, and the maximum distance that the front of fluorescein travelled was measured to the nearest half millimetre. The starting volume was $1.5 \mu \mathrm{l}(1.3 \mu \mathrm{l}$ was found to wet the end of the strip up to the notch at $5 \mathrm{~mm}$ ) with $0.5 \mu \mathrm{l}$ steps up to $15 \mu \mathrm{l}$. The test was then repeated five times on three separate occasions, in which the time taken for the fluorescein front to reach each millimetre up to the maximum distance (as determined from the volume-distance measurements) was recorded. Recording was done with a computer program with a continuous time display.

\section{Results}

PART ONE: FLUORESCEIN FILTER PAPER STRIP COMPARED WITH EQUIVALENT AMOUNT OF FLUORESCEIN

In all, 168 subjects were included (mean age 66.3 years, SD 14.9), comprising 42 patients with known definite Sjögren's syndrome, 32 patients with meibomian gland disease attending the external eye disease clinic, and 126 patients with a healthy ocular surface attending for visual deterioration due to cataract formation or age related macular degeneration. Subjects were consecutively divided into four groups so that each group contained similar proportions (1:1:3) of patients with Sjögren's syndrome and or meibomian gland dysfunction and subjects with a healthy ocular surface. Group 1: right eye: $1.3 \mu 10.5 \%$ fluorescein; left eye: prepared strip, 60 subjects 
Table 1 Prepared strip containing $1.3 \mu \mathrm{l} 0.5 \%$ fluorescein into left eye (group 1) or right eye (group 2), and $1.3 \mu \mathrm{l}$ of $0.5 \%$ placed into inferior fornix of fellow eye. Schirmer's test read after 3 minutes. A TCR of 1 reflects a concentration of fluorescein of $0.5 \%$ at 3 minutes. Log TFI is the natural logarithm

\begin{tabular}{|c|c|c|c|c|c|c|}
\hline & \multicolumn{2}{|c|}{ Schirmer (mm) } & \multicolumn{2}{|l|}{$T C R$} & \multicolumn{2}{|c|}{$\log T F I$} \\
\hline & Right & left & Right & Left & Right & Left \\
\hline \multicolumn{7}{|c|}{ Prepared strip into left eye and drop into right eye } \\
\hline $\begin{array}{l}\text { Mean } \\
\text { (SD) }\end{array}$ & $\begin{array}{l}19.50 \\
(17.1)\end{array}$ & $\begin{array}{l}17.97 \\
(15.4)\end{array}$ & $\begin{array}{l}0.057 \\
(0.11)\end{array}$ & $\begin{array}{l}0.070 \\
(0.13)\end{array}$ & $\begin{array}{l}5.83 \\
(6.28)\end{array}$ & $\begin{array}{l}5.55 \\
(5.89)\end{array}$ \\
\hline p Value & & 0.14 & & 0.28 & & 0.77 \\
\hline \multicolumn{7}{|c|}{ Prepared strip into right eye and drop into left eye } \\
\hline Mean & $\begin{array}{l}12.47 \\
(10.5)\end{array}$ & $\begin{array}{l}13.67 \\
(10.6)\end{array}$ & $\begin{array}{l}0.091 \\
(0.16)\end{array}$ & $\begin{array}{r}0.090 \\
(0.14)\end{array}$ & $\begin{array}{l}4.94 \\
(5.45)\end{array}$ & $\begin{array}{l}5.02 \\
(5.78)\end{array}$ \\
\hline $\mathrm{p}$ Value & & 0.93 & & 0.18 & & 0.31 \\
\hline
\end{tabular}

Table $21.3 \mu$ l of $0.5 \%$ fluorescein into both eyes (group 3). Schirmer's test read after 3 minutes. A TCR of 1 reflects a concentration of fluorescein of $0.5 \%$ at 3 minutes. Log TFI is the natural logarithm

\begin{tabular}{|c|c|c|c|c|c|c|}
\hline & \multicolumn{2}{|c|}{ Schirmer (mm) } & \multicolumn{2}{|l|}{$T C R$} & \multicolumn{2}{|c|}{$\log T F I$} \\
\hline & Right & Left & Right & Left & Right & Left \\
\hline $\begin{array}{l}\text { Mean } \\
\text { (SD) } \\
\text { p Value }\end{array}$ & $\begin{array}{l}23.59 \\
(14.6)\end{array}$ & $\begin{array}{r}20.88 \\
(11.5) \\
0.44\end{array}$ & $\begin{array}{l}0.04 \\
(0.13)\end{array}$ & $\begin{array}{c}0.05 \\
(0.12) \\
0.10\end{array}$ & $\begin{array}{l}6.44 \\
(6.88)\end{array}$ & $\begin{array}{c}5.95 \\
(6.69) \\
0.31\end{array}$ \\
\hline
\end{tabular}

Table 3 Prepared filter paper strips containing $1.3 \mu$ l of $0.5 \%$ fluorescein, placed into both eyes (group 4). Schirmer's test read after 3 minutes. A TCR of 1 reflects a concentration of fluorescein of $0.5 \%$ at 3 minutes. Log TFI is the natural logarithm

\begin{tabular}{|c|c|c|c|c|c|c|}
\hline & \multicolumn{2}{|c|}{ Schirmer (mm) } & \multicolumn{2}{|l|}{$T C R$} & \multicolumn{2}{|c|}{$\log T F I$} \\
\hline & Right & Left & Right & Left & Right & Left \\
\hline $\begin{array}{l}\text { Mean } \\
\text { (SD) } \\
\text { p Value }\end{array}$ & $\begin{array}{l}15.81 \\
(10.1)\end{array}$ & $\begin{array}{r}17.63 \\
(10.8) \\
0.93\end{array}$ & $\begin{array}{l}0.08 \\
(0.18)\end{array}$ & $\begin{array}{c}0.09 \\
(0.19) \\
0.86\end{array}$ & $\begin{array}{l}5.24 \\
(5.87)\end{array}$ & $\begin{aligned} & 5.28 \\
&(5.95) \\
& 0.53\end{aligned}$ \\
\hline
\end{tabular}

Group 2: right eye: prepared strip; left eye: 1.3 $\mu 10.5 \%$ fluorescein, 40 subjects

Group 3: both eyes: $1.3 \mu 1$ of $0.5 \%$ fluorescein, 30 subjects

Group 4: both eyes: prepared strip, 38 subjects.

Groups 1 and 2

There was no significant interocular difference in the Schirmer's test, TCR, or TFI, whether a prepared strip or drop was used to perform the test (Tables 1-3). There was no significant interocular difference in the Schirmer's, TCR, or TFI using a prepared strip in one eye and a drop in the other eye (Tables 1-3). Furthermore, there was no significant difference in the Schirmer's, TCR, or TFI, whether a prepared strip or drop of fluorescein was placed in the right or left eye, respectively (Table 1) (groups 3 and 4). The interocular similarity was apparent over a wide range of values for the Schirmer's test, TCR, and TFI- that is, there was no correlation between the interocular difference in Schirmer's test or TFI and the mean interocular value $(p=0.47$ and $p=0.65)$. There was a significant correlation between right and left eyes using a prepared strip, drop or combination, for both the Schirmer's test $(r=0.94$, $0.81,0.86, \mathrm{p}<0.001)$ and the TFI $(r=0.94$, $0.73,0.57, \mathrm{p}<0.001)$.

The variability of one observer in reading the Schirmer's, TCR, and the resultant TFI, was assessed by comparing the within-eye variance of three independent readings using both the prepared strip and drop of fluorescein. This was done for the prepared strips into the right eye and drop into the left, and then vice versa. There was no significant difference in the within-eye variance of the Schirmer's, TCR, or TFI whether the drop was placed into the right or left eye, respectively $(p=0.39)$. The reliability, therefore, of measuring and reading the Schirmer's test, TCR, and TFI was not dependent on whether a prepared strip or drop of fluorescein was used. There was a significant linear correlation between the Schirmer's test and the TFI, for the prepared strips and drops $\left(r=0.82\right.$ and $0.79, \mathrm{p}=2 \times 10^{-23}$ and $\left.\mathrm{p}=7 \times 10^{-22}\right)$. There was no difference in the coefficient of regression whether a prepared strip or drop was used (Fisher's z transformation on $r$, $\mathrm{p}=0.78)$.

\section{Groups 3 and 4}

On comparing a prepared strip with a drop into both eyes (Tables 2 and 3), there was no significant difference in the mean interocular difference for the Schirmer's test using a drop (2.71, SD 8.54) or a prepared strip (1.82, SD 3.73) $(\mathrm{p}=0.09)$. The mean and variance of the interocular difference ratio for the TFI was, however, lower using a strip (1.08, SD 0.98) than using a drop (2.91, SD 4.29) $(\mathrm{p}=0.001$ and $\mathrm{p}=0.01$ ).

\section{PART TWO. TFI: STANDARD METHOD VERSUS} PREPARED FILTER PAPER STRIP

One hundred patients, 30 with a known definite diagnosis of Sjögren's syndrome, 30 patients with meibomian gland disease, and 34 patients with a healthy ocular surface attending for visual deterioration due to cataract formation or age related macular degeneration were included. The average age for patients with Sjögren's syndrome was 67.3 (SD 14.33, female:male 4.2:1) and those without Sjögren's syndrome was 62.5 (SD 13.8, female:male $3: 2.2)$.

Without and with topical anaesthesia

For both patients with and without Sjögren's syndrome, there was no significant difference in the mean Schirmer's test, TCR, or TFI for the prepared strip and drop, whether topical anaesthesia was or was not used (Tables 4 and 5). Six patients without Sjögren's syndrome had Schirmer's test values equal to or less than $5 \mathrm{~mm}$. No subject without Sjögren's syndrome, however, had a TFI of less than 40 . There was no significant difference between subjects with MGD and those subjects with no external eye disease for the Schirmer's test $(p=0.79), T C R$ $(p=0.66)$, or TFI $(p=0.61)$.

\section{Anaesthetic versus no anaesthetic}

For the group of patients without Sjögren's syndrome, there was a significant difference in the Schirmer's test without and with anaesthetic, for the prepared strip $(\mathrm{p}=0.03)$ and drop $(p=0.005)$, respectively. Likewise there was a significant difference in the TCR and TFI for the prepared strip $(p=0.02, p=0.002)$ and drop $(p=0.005, p=0.001)$, respectively. For the patients with Sjögren's syndrome, however, there was no significant difference in the Schirmer's test $(p=0.57$ and $p=0.78)$, TCR 
Table 4 Prepared strip (Pre-S) containing $1.3 \mu \mathrm{l}$ of $0.5 \%$ fuorescein placed into the inferior fornix 5 minutes after instilling $10 \mu \mathrm{l}$ of $0.5 \%$ fluorescein into inferior fornix of the fellow eye. Schirmer's test read after 5 minutes. No anaesthetic used. A TCR of 1 , reflects a concentration of fluorescein of $0.5 \%$ at 5 minutes. Log TFI is the natural logarithm

\begin{tabular}{|c|c|c|c|c|c|c|}
\hline & \multicolumn{2}{|c|}{ Schirmer (mm) } & \multicolumn{2}{|l|}{$T C R$} & \multicolumn{2}{|l|}{$T F I$} \\
\hline & Pre-S & Drop & Pre-S & Drop & Pre-S & Drop \\
\hline \multicolumn{7}{|c|}{ Non-Sjögren's syndrome } \\
\hline Mean & 13.7 & 14.7 & 0.058 & 0.055 & 375 & 457 \\
\hline SD & 6.36 & 7.14 & 0.034 & 0.035 & 395 & 490 \\
\hline $\mathrm{p}$ Value & & 0.36 & & 0.73 & & 0.88 \\
\hline \multicolumn{7}{|c|}{ Sjögren's syndrome } \\
\hline Mean & 2.53 & 2.66 & 0.279 & 0.295 & 11.7 & 11.6 \\
\hline SD & 1.55 & 1.84 & 0.154 & 0.184 & 9.72 & 8.89 \\
\hline $\mathrm{p}$ Value & & 0.37 & & 0.36 & & 0.64 \\
\hline
\end{tabular}

Table 5 Prepared strip (Pre-S) containing $1.3 \mu$ l of $0.5 \%$ fluorescein placed into inferior fornix 5 minutes after instilling $10 \mu \mathrm{l}$ of $0.4 \%$ benoxinate into the same eye and 5 minutes after instilling $10 \mu \mathrm{l}$ of $0.5 \%$ fluorescein diluted in $0.4 \%$ benoxinate into the fellow eye. Schirmer's test read after 5 minutes. A TCR of 1 reflects a concentration of fluorescein of $0.5 \%$ at 5 minutes. Log TFI is the natural logarithm

\begin{tabular}{|c|c|c|c|c|c|c|}
\hline & \multicolumn{2}{|c|}{ Schirmer (mm) } & \multicolumn{2}{|l|}{$T C R$} & \multicolumn{2}{|l|}{$T F I$} \\
\hline & Pre-S & Drop & Pre-S & Drop & Pre-S & Drop \\
\hline \multicolumn{7}{|c|}{ Non-Sjögren's syndrome } \\
\hline Mean & 11.5 & 11.5 & 0.072 & 0.073 & 207 & 221 \\
\hline SD & 4.68 & 5.10 & 0.035 & 0.037 & 157 & 186 \\
\hline $\mathrm{p}$ Value & & 0.52 & & 0.618 & & 0.19 \\
\hline \multicolumn{7}{|c|}{ Sjögren's syndrome } \\
\hline Mean & 2.29 & 2.54 & 0.438 & 0.357 & 8.61 & 10.4 \\
\hline $\mathrm{SD}$ & 1.66 & 1.34 & 0.298 & 0.225 & 7.97 & 7.85 \\
\hline $\mathrm{p}$ Value & & 0.27 & & 0.152 & & 0.94 \\
\hline
\end{tabular}

$(p=0.02$ and $p=0.26)$, or TFI $(p=0.20$ and $\mathrm{p}=0.60$ ) for both the prepared strip and drop, whether topical anaesthesia was or was not used.

PART THREE: IN VITRO RESULTS

As the filter paper used was $5 \mathrm{~mm}$ in diameter for the first $15 \mathrm{~mm}$ and $6.5 \mathrm{~mm}$ in diameter for the remainder of the strip, the measurements were separated into two groups, $5-15 \mathrm{~mm}$ and greater than $15 \mathrm{~mm}$.

Volume-distance relation

The relation between volume and distance travelled on the filter paper, was best approximated by the quadratic function $\mathrm{D}=2.05$ $+2.38 \mathrm{~V}-0.042 \mathrm{~V}^{2}(r=0.998, \mathrm{p}<0.001)$ for volumes $0-15 \mu \mathrm{l}(0-28.5 \mathrm{~mm})$, using a computer generated least squares approximation (sPss version 9) to the data. We found a greater distance travelled for a given volume than that of Lamberts et al. ${ }^{21}$ Although this may reflect a variation in the filter paper, it may relate to the presence of fluorescein. We found that fluorescein allowed the front to be easily identified, which is not always possible when using water alone. That is, one is more likely to underestimate the distance travelled by the wave front using water. We do not know, however, if the fluorescein itself moves at a different rate from either water or an electrolyte concentration as is found in tears.

\section{Volume-distance-time}

The time taken for a given volume to reach the maximum distance along the filter paper could be approximated by the power function, time = $2.2+\mathrm{V}^{1.5}(r=0.9 \mathrm{p}<0.001)$, using a computer generated least squares approximation (SPSS) to the data. The time taken for a given volume to

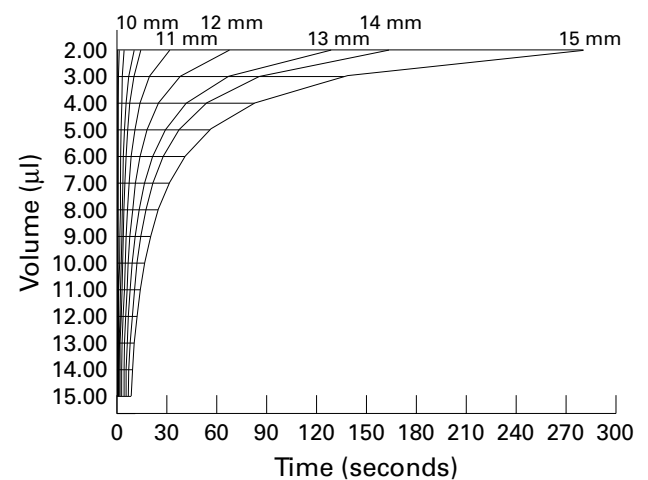

Figure 2 In vitro data: volume, distance, and time relation. Curves demonstrate time taken for a given volume to travel a given distance. Each of the 10 curves from left to right $(15 \mathrm{~mm}$ to $6 \mathrm{~mm})$, represent the distance travelled along the filter paper strip as measured from the filter paper notch. For example, if the filter paper is removed from the eye after 30 seconds and the distance as measured from the notch is $8 \mathrm{~mm}$, this indicates that the filter paper was in contact with at least $5 \mu$ l of tears.

move a specified distance also followed a power function $(r>0.92 \mathrm{p}<0.001$ for the distances $5-15$ in $1 \mathrm{~mm}$ steps) and is shown in Figure 2. In essence, larger volumes moved more quickly than smaller volumes. As shown in Figure 2, a volume of $5 \mu \mathrm{l}$ took 7 seconds to travel $10 \mathrm{~mm}$, while a volume of $10 \mu \mathrm{l}$ took 3.5 seconds to travel $10 \mathrm{~mm}$. Extrapolating to the in vivo situation, removing the filter paper from the eye after any length of time, and measuring the distance travelled, allows one to determine the volume of tears that was in contact with the filter strip. For example, if the filter strips are removed after 1 minute, and the distances travelled as measured from the notch $(5 \mathrm{~mm}$ from the end) are $15 \mathrm{~mm}$ and $13 \mathrm{~mm}$, this reflects a volume of tears of at least $10 \mu \mathrm{l}$ and $8 \mu \mathrm{l}$, respectively. Alternatively, if the filter paper strips are removed after $1 / 2$ minute and the distances travelled, as measured from the notch, are $10 \mathrm{~mm}$ and $8 \mathrm{~mm}$, this reflects a volume of tears of at least $7 \mu \mathrm{l}$ and $5 \mu \mathrm{l}$, respectively.

\section{Theoretical TFI}

If one considers the starting volume of tears as $\mathrm{V}_{0}$, the production of tears or rate of inflow as I, the rate of loss of tears due to evaporation as $\mathrm{P}$, the rate of loss of tears due to outflow as $\mathrm{E}$, then the net rate of inflow $\left(I_{N}\right)$ is $I-P$, and the net rate of flow $(\mathrm{N})$ either into or out of the eye is, therefore, $\mathrm{I}_{\mathrm{N}}-\mathrm{E}$. If a substance such as fluorescein is added to the tears, and assuming immediate and perfect mixing, then loss of fluorescein only occurs from outflow - that is, E. Although there is likely to be some compartmentalisation the following analysis is generally applicable. The rate of change in concentration of a substance added to the tears is proportional to the concentration of the substance and inflow and inversely proportional to the sum of the volume and net flow-that is, $\mathrm{dC}(\mathrm{t}) / \mathrm{dt} \sim-\mathrm{C}(\mathrm{t}) \mathrm{I}_{\mathrm{N}} /\left(\mathrm{V}_{0}+\mathrm{Nt}\right)$

If the volume of tears remains constant, equal to the initial volume $\left(\mathrm{V}_{0}\right)$-that is $\mathrm{E}=\mathrm{I}_{\mathrm{N}}$, so that $\mathrm{N}=0$ then solving equation (1), the concentration of fluorescein at a time $t$, can be calculated from

$$
\mathrm{C}(\mathrm{t})=\mathrm{C}(0) \mathrm{e}^{-\mathrm{I} t / \mathrm{N} 0}
$$


where $\mathrm{C}(0)$ is the starting concentration-that is, when $t=0$. For example, if the volume of tears is approximately $7 \mu 1^{22}{ }^{23}$ and the net inflow equal to outflow is $1 \mu \mathrm{l}^{22}{ }^{23}$ the concentration after 5 minutes would reduce to $C(5)=$ $0.49 \mathrm{C}(0)$.

If, however, the net inflow $\mathrm{I}_{\mathrm{N}}$ and outflow $\mathrm{E}$ differ-that is, $\mathrm{N} \neq 0$, then the volume of tears will change, so that the volume at some time $t$ will be $\mathrm{V}(\mathrm{t})=\mathrm{V}_{0}+\mathrm{Nt}$. Solving equation (1), where $\mathrm{N}$ is not zero, leads to

$\mathrm{Ln} \mathrm{C}(\mathrm{t})+\mathrm{Ln}\left(\mathrm{I}+\mathrm{Nt} / \mathrm{V}_{0}\right)^{\mathrm{IN}}=\mathrm{K}$

where $\mathrm{K}$ is a constant. When $\mathrm{t}=0$, the starting concentration $\mathrm{C}(0)$

$\operatorname{Ln} \mathrm{C}(0)+\operatorname{Ln}\left(\mathrm{I} / \mathrm{V}_{0}\right)^{\mathrm{IN}}=\mathrm{K}$

Substituting equation (4) into equation (3), $\mathrm{N} \neq 0$, the concentration $\mathrm{C}(\mathrm{t})$ of fluorescein at time $(\mathrm{t})$, follows the relation

$\mathrm{C}(\mathrm{t})=\mathrm{C}(0) /\left(1+\mathrm{Nt} / \mathrm{V}_{0}\right)^{\mathrm{IN}}$

In this scenario where, say, $\mathrm{I}_{\mathrm{N}}>\mathrm{E}$ due to, say, reflex epiphora, then if $I_{N}$ increases to $4 \mu \mathrm{l} / \mathrm{min}$ for 5 minutes, and $\mathrm{E}$ remains at $1 \mu \mathrm{l} / \mathrm{min}$, the concentration after 5 minutes, assuming a starting volume of $7 \mu \mathrm{l}$, would be $\mathrm{C}(5)=$ $0.22 \mathrm{C}(0)$.

Although it is unclear what effect $10 \mu \mathrm{l}$ of fluorescein instilled 5 minutes before performing the TFI would have on the tear volume and concentration, a prediction based on the above models can be made. The addition of a $10 \mu \mathrm{l}$ drop of fluorescein would increase the volume to $17 \mu \mathrm{l}$, with a starting fluorescein concentration $\mathrm{C}(0)$ of $10 / 17 \times 0.5 \%$ ( $0.5 \%$ fluorescein, represents a TCR of 1 ). If, after 5 minutes, one makes the assumption that the tear volume has returned to $7 \mu \mathrm{l}$, then the outflow over this 5 minute period would have been $15 \mu$ or 3 $\mu \mathrm{l} / \mathrm{min}$ (inflow $1 \mu \mathrm{l} / \mathrm{min}$ over this period). The difference $(N)$ between inflow $(1 \mu \mathrm{l})$ and outflow over this 5 minute period would then be $-2 \mu \mathrm{l} / \mathrm{min}$, so that the change in concentration of fluorescein after the first 5 minutes would be $\mathrm{C}(5)=0.38$ (or 0.64 for $2 \mu 1$ starting tear volume and a net inflow of $0.3 \mu \mathrm{l} / \mathrm{min}$ and outflow of $2.3 \mu \mathrm{l} / \mathrm{min}$ ). The concentration of fluorescein after the second 5 minutes when the TFI is measured would then be $\mathrm{C}(10)=$ $0.38 \times \mathrm{e}^{-1 \times 5 / 7}=0.18(0.30$ for $2 \mu$ l starting tear volume). Thus, the expected TCR would be 0.18 , giving an expected TFI (assuming a Schirmer's value of $12 \mathrm{~mm}$ ) of 67 , or 10 for a patient with Sjögren's syndrome, assuming 3 $\mathrm{mm}$ for the Schirmer's test (equivalent to a volume of $2 \mu \mathrm{l}$ ). Patients with KCS have been reported to have I of $<0.5 \mu \mathrm{l} / \mathrm{min} .{ }^{24-26}$ An I of 0.5 corresponds (from Mishima et $a l^{22}$ and Jordan and Baum ${ }^{23}$ ) to a volume of approximately $2 \mu \mathrm{l}$.

Using a prepared strip containing $6.5 \mu \mathrm{g}$ of fluorescein $(1.3 \mu \mathrm{l} \times 0.5 \%)$, the starting concentration would be $6.5 \mu \mathrm{g} / 7 \mu \mathrm{l}$, which is equivalent to a TCR of $6.5 / 35$, where $0.5 \%$ fluorescein $(5 \mu \mathrm{g} / \mu \mathrm{l})$ represents a TCR of 1 . The TCR after 5 minutes would be $\mathrm{C}(5)=$ $6.5 / 35 \mathrm{e}^{-1 \times 5 / 7}=0.09$, for a starting volume of 7 $\mu l$ giving a TFI of 133 . For a patient with Sjögren's syndrome the TCR for a tear volume of $2 \mu \mathrm{l}$ would be 0.31 and assuming a Schirmer's test value of $3 \mathrm{~mm}$, the TFI would be 9.7 . These values - that is, 9.5-10 for a subject with
Sjögren's syndrome, are similar to the observed values, while those expected for a subject without Sjögren's syndrome-that is, 67-133, are less than found. This very likely reflects the reflex secretion from the fluorescein and filter paper present in healthy subjects but usually absent in subjects with Sjögren's syndrome. ${ }^{19}{ }^{27}$ For example, if stimulation from the filter strip increases the inflow to $2 \mu \mathrm{l} / \mathrm{min}$, the TCR would reduce to 0.058 using a drop and 0.045 using a strip, which translates to a TFI of $12 / 0.058=207$ and $12 / 0.045=267$, respectively. This is also suggested if the values obtained by Mathers $e t a l^{1124}$ for tear volumes and Schirmer's tests are considered. In the age group 61-70 years, they found a much lower normal tear volume of $1.73 \mu \mathrm{l}$ with an inflow of $0.12 \mu \mathrm{l} / \mathrm{min}$, much less than has previously been reported. Using these values, the change in concentration would be 0.35 giving a predicted TFI of 34 using a Schirmer's value of $12 \mathrm{~mm}$ reported by Mather et $a l^{1124}$ for this age range, which is much less than found in this study or in that by Xu et al. ${ }^{9}$ A Schirmer's value of $12 \mathrm{~mm}$ corresponds to a tear volume in contact with the filter paper of at least $8 \mu \mathrm{l}$ which, taken together with the TFI found in this study and that of $\mathrm{Xu}$ et $a l,{ }^{9}$ indicates a substantial reflex component in non-Sjögren's subjects.

\section{Discussion}

The Schirmer's test remains the most popular test for the diagnosis of dry eye syndrome. Its poor sensitivity, specificity, and reproducibility $^{1-6}$ often leads to equivocal results. Many other tests have therefore been introduced for the diagnosis of dry eye, such as tear break up time, ${ }^{28}$ lactoferrin, ${ }^{29}{ }^{30}$ immunological assay, vital staining of the ocular surface, ${ }^{3}$ tear meniscus, ${ }^{4}$ height or tear osmolarity, ${ }^{31}$ among others. These tests reflect different aspects of the tear film, each providing different qualitative information. The Schirmer's test, however, is easy to perform and, without the need for any additional equipment, has generalised applicability. Some of the variables associated with the Schirmer's test have been overcome by the introduction of the TFI. ${ }^{9}$ A component of the TFI- that is the TCR, gives an indication of the dilution of fluorescein (on a doubling scale) that has occurred in the tear film. Using the TCR as the denominator in the calculation of the TFI, results in a $2^{\mathrm{n}}$ amplification of the Schirmer's test value. This may account for the improved sensitivity and specificity of the TFI for the diagnosis of dry eye, and for distinguishing between Sjögren's and non-Sjögren's dry eye syndromes. ${ }^{9}$ A micropipette, however, is needed to instil the correct amount and concentration of fluorescein into each eye and it is necessary for the Schirmer's test to be performed at a specific time after instillation of fluorescein into the conjunctival fornix. These practical factors limit the general application of the TFI in practice.

The first part of this study shows that using a prepared strip is equivalent in terms of the Schirmer's test, TCR, and TFI to placing the equivalent amount of fluorescein in the con- 
junctival fornix using a drop. Although the dynamics of the prepared strip to a $1.3 \mu \mathrm{l}$ drop must differ, the equivalence of the two methods in terms of the above parameters, suggests that the filter paper strip collects the majority of the non-bound component of the tear film and is an adequate delivery system of fluorescein. This allowed a comparison to be made between the standard and modified technique for measuring the TFI. The dynamics of the standard TFI are also different. The added volume of $10 \mu \mathrm{l}$ is likely to have a considerable effect on tear dynamics, particularly over the 5 minutes before measurement of the TFI, depending on drainage, evaporation, and effect on tear production. The assumption that the tear volume has returned to its resting volume at the commencement of the test is likely to be inaccurate. Thus although there appeared to be no apparent difference in the Schirmer's test, TCR, or TFI between the standard and modified method, the significant decrease in interocular variability using the prepared strip, is likely to reflect the variation in drainage which occurs with the standard method.

The method proposed for performing the TFI, does not require additional equipment to instil the correct amount and concentration of fluorescein into the eye, and is not dependent on performing the Schirmer's test after a specific time. The TFI upper $95 \%$ confidence interval using prepared strips for the diagnosis of Sjögren's syndrome, was 15 without and 12 with anaesthetic - an approximate Schirmer's test value of 3 and a TCR of 0.25 or 1:4. The TFI was found to more reliably distinguish between patients with Sjögren's syndrome than those without. That is, there were six subjects without Sjögren's syndrome who had Schirmer's test values equal to or less than $5 \mathrm{~mm}$. There were no subjects without Sjögren's syndrome, however, who had a TFI of less than 40. Although tear production $\mathrm{may}^{24}$ or may not ${ }^{1}$ be dependent on sex and age, it is not clear if patients with Sjögren's syndrome (where females predominate) experience a similar effect. Future studies will determine if the proposed confidence levels need to be adjusted for age and sex-particularly for an early age of onset of Sjögren's syndrome.

The use of prepared strips thus provide a simple reliable method for performing the TCR and TFI, and is well suited to the general practitioner or primary care department. It allows both ophthalmologists and nonophthalmologists to identify patients who may be suffering from Sjögren's syndrome. The further investigation of such patients can then proceed along established criteria for the diagnosis of Sjögren's syndrome.

The in vitro test data provides useful information, particularly for those situations, where the patient is unable to tolerate the filter strip for 5 minutes. It also allows the observer to remove the filter strip at any time interval and to estimate the approximate volume of tears that the filter paper was in contact with.

We thank Rebecca Kaye for help with collection of the in vitro data.

1 Henderson JW, Prough WA. Influence of age and sex on flow of tears. Arch Ophthalmol 1950;43:224-31.

2 Clinch ET, Benedetto DA, Felberg NT, et al. Schirmer's test: a closer look. Arch Ophthalmol 1983;101:1383-6.

3 Van Bijsterveld OP. Diagnostic tests in the sicca syndrome. Arch Ophthalmol 1969;82:10-14.

4 Goren MB, Goren SB. Diagnostic tests in patients with symptoms of keratoconjunctivitis sicca. Am $\mathcal{F}$ Ophthalmol 1988;106:570-4.

5 Wright JC, Meger GE. A review of the Schirmer test for tear production. Arch Ophthalmol 1962;67:564-5.

6 Pirschmidt NW. Evaluation of the Schirmer tear test. South Med F 1970;63:1256.

7 Ono M, Yoshino K, Ogawa Y, et al. Tear clearance rate in normal and dry eye patients. Invest Ophthalmol Vis Sci (suppl) 1991;32:1113.

8 Zappia RJ, Milder B. Lacrimal drainage function, II: the fluorescein dye disappearance test. Am $\mathcal{F}$ Ophthalmol 1972; 74:160-2.

$9 \mathrm{Xu}$ KP, Yagi Y, Toda I, et al. Tear function index. Arch Ophthalmol 1995;113:84-8.

10 Mathers WD, Binarao G, Petroll M. Ocular water evaporation and the dry eye: a new measuring device. Cornea 1993;12:335-40.

11 Mathers WD, Daley TE. Tear flow and evaporation in patients with and without dry eye. Ophthalmology 1996; 103:664-9.

12 Tsubota K, Yamada M. Tear evaporation from the ocular surface. Invest Ophthalmol Vis Sci 1992;33:2942-50.

13 Vitali C, Bombardieri S, Moutsopoulos HM, et al. Preliminary criteria for the classification of Sjogren's syndrome. Arthritis Rheum 1993;36:340-7.

4 Sreebny LM, Valdini A. Xerostomia: a neglected symptom. Arch Intern Med 1987;147:1333-7.

15 Markusse HM, Pillay M, Breedveld FB. The diagnostic value of salivary gland scintigraphy in patients suspected of primary Sjogren's syndrome. Br F Rheumatol 1993;32:2315.

16 Field EA, Longman LP, Bucknall R, et al. The establishment of a xerostomia clinic: a prospective study. $\mathrm{Br} \mathcal{7}$ Oral Max Fac Surg 1997;35:96-103.

17 Bron AJ, Benjamin L, Snibson GR. Meibomian gland disease: classification and grading of lid changes. Eye 1991; 5:395-411.

18 Shimazaki J, Sakata M, Tsubota K. Ocular surface changes and discomfort in patients with meibomian gland dysfunction. Arch Ophthalmol 1995;113:1266-70.

19 Pflugfelder SC, Tseng SCG, Sanabria O, et al. Evaluation of subjective assessments and objective diagnostic tests for diagnosing tear-film disorders known to cause ocular irritation. Cornea 1998;17:38-56.

20 Mathers WD, Shields WJ, Sachdev MS, et al. Meibomian gland dysfunction in chronic blepharitis. Cornea 1991;10: 277-85.

21 Lamberts DW, Foster CS, Perry HD. The Schirmer test after topical anesthesia, and the tear meniscus height in after topical anesthesia, and the tear meniscus

22 Mishima S, Gasset A, Klyce SD, et al. Determination of tear volume and tear flow. Invest Ophthalmol 1966;5:264-76.

23 Jordan A, Baum J. Basic tear flow. Ophthalmology 1980;87: 920-30.

24 Mathers WD, Lane JA, Zimmerman MB. Tear film changes associated with normal ageing. Cornea 1996;15:229-34

25 Mishima S, Kubota Z, Farris RL. The tear flow dynamics in normal and keratoconjunctivitis sicca cases. Excerpta Medica Int Congr Ser 1970;222:1801-5.

26 Scherz W, Doane MG, Dohlman CH. Tear volume in normal eyes and keratoconjunctivitis sicca. Albrecht von Graefes Arch Ophthalmol 1974;192:141-50.

27 Tsubota K. The importance of the Schirmer's test with Tsubota K. The importance of the Schirmer's test
nasal stimulation. Am $\mathcal{f}$ Ophthalmol 1991;111:106-8.

28 Vanley BA, Leopold IH, Gregg TH. Interpretation of the tear film break up. Arch Ophthalmol 1977;95:445.

29 Kijlstra A, Jeurissen SHM, Koning KM. Lactoferrin levels in human tears. Br f Ophthalmol 1983;67:199.

30 Bonavida B, Sapse AT. Human tear lysozyme. II. Quantitative determination with standard Schirmer strips. $A m$ F Ophthalmol 1968;66:70.

31 Gilbard JP, Farris RL, Santamaria J. Osmolarity of tear microvolumes in keratoconjunctivitis sicca. Arch Ophthalmol 1978;96:677. 